\title{
Effect of Botanical Extracts on the Population Density of Fusarium oxysporum in Soil and Control of Fusarium Wilt in the Greenhouse
}

\author{
John H. Bowers and James C. Locke, USDA, ARS, U.S. National Arboretum, Floral \& Nursery Plants Research \\ Unit, Rm. 238, B-010A, BARC-W, Beltsville, MD 20705
}

\begin{abstract}
Bowers, J. H., and Locke, J. C. 2000. Effect of botanical extracts on the population density of Fusarium oxysporum in soil and control of Fusarium wilt in the greenhouse. Plant Dis. 84:300305.

Several commercial formulations of botanical extracts and essential oils are being investigated as possible alternatives to soil fumigation for control of Fusarium wilt diseases. Soil infested with Fusarium oxysporum f. sp. chrysanthemi was treated with 1, 5, and $10 \%$ aqueous emulsions of formulated extracts of clove ( $70 \%$ clove oil), neem ( $90 \%$ neem oil), pepper/mustard (chili pepper extract and essential oil of mustard), cassia (extract of cassia tree), and Banrot (a standard fungicide applied at different labeled rates) in separate experiments. Population densities of $F$. oxysporum f. sp. chrysanthemi were determined at 0 (before treatment), 1, 3, 7, 14, and 21 days after treatment. Treatment of the soil with 5 and $10 \%$ aqueous emulsions resulted in significant $(P<0.05)$ differences among treatment means at each assay date. After 3 days, pepper/mustard, cassia, and clove extracts added as $10 \%$ aqueous emulsions reduced the population density of F. oxysporum f. sp. chrysanthemi $99.9,96.1$, and $97.5 \%$, respectively, compared with the untreated control. Neem oil extract increased the population density of $F$. oxysporum f. sp. chrysanthemi at all concentrations tested. Banrot did not reduce the population density of $F$. oxysporum f. sp. chrysanthemi in any experiment. In a second, related experiment, soil infested with Fusarium oxysporum f. sp. melonis also was treated with 1, 5, and $10 \%$ aqueous emulsions of formulated extracts, incubated in closed plastic bags for 1 week, and planted with muskmelon seeds (cv. Gold Star) in the greenhouse. Treatment of infested soil with 5 and $10 \%$ aqueous emulsions of the botanical extracts resulted in differences among treatments after 5 to 6 weeks. The pepper/mustard, cassia, and clove extracts suppressed disease development in repeated experiments (80 to $100 \%$ healthy plant stand) compared with the untreated infested soil $(<20 \%$ stand). The observed reduction in the pathogen population and increased healthy plant stand in the greenhouse indicates that these extracts could have important roles in biologically based management strategies for control of Fusarium wilt diseases.
\end{abstract}

Fusarium wilts, caused by Fusarium oxysporum Schlechtend.:Fr., are some of the most widespread and destructive diseases of many major ornamental and horticultural crops. This soilborne fungus causes vascular wilts by infecting plants through the roots and growing internally through the cortex to the stele $(3,35)$. The vascular tissues of the root, and then the stem, are

Corresponding author: J. H. Bowers

E-mail: jbowers@asrr.arsusda.gov

Mention of a trademark or proprietary product does not constitute a guarantee or warranty of the product by the U.S. Department of Agriculture, and does not imply its approval to the exclusion of other products that also may be suitable.

* The $\boldsymbol{e}$-Xtra logo stands for "electronic extra" and indicates the HTML abstract available on-line contains supplemental material not included in the print edition.

Accepted for publication 22 November 1999.

Publication no. D-2000-0114-01R

This article is in the public domain and not copyrightable. It may be freely reprinted with customary crediting of the source. The American Phytopathological Society, 2000. colonized by growth of hyphae and movement of conidia in the transpiration stream. Initial symptoms appear as chlorosis and distortion of the lower leaves, often on one side of the plant. Foliar chlorosis, necrosis, and plant stunting become more pronounced as the disease progresses. Wilting occurs on the affected side of the plant, followed by vascular discoloration and stem necrosis. The entire plant wilts and dies as the pathogen moves into the stem.

Currently, preplant soil fumigation and fungicide applications are used to control wilts and other diseases caused by soilborne pathogens on high-value crops. However, the major fumigant used, methyl bromide, has been defined by the Montreal Protocol of 1991 as a chemical that contributes to the depletion of the ozone layer. The U.S. Clean Air Act (Section 602) requires that production and importation of any substance defined as an ozone depleter by the Montreal Protocol be phased out. In the United States, a phaseout date of 1 January 2005 has been legislated. The Food Quality Protection Act of 1996 may further limit growers' options due to the requirement that all pesticides be reregistered with lower residue tolerances, which may result in label restrictions and pesticide losses.

The long-term goal of our research is to develop and evaluate new or existing alternative control methods for soilborne plant pathogens to replace methyl bromide and fungicides in ornamental and horticultural crop production systems. Biologically based and environmentally safe alternatives, such as biological control agents, natural plant products, and cultural methods, are being investigated for possible use as components in integrated management programs.

Many plants and plant products have been reported to possess pest control properties $(11,12)$. Although much of the literature on natural products in the agricultural field concerns insect control, a smaller but emerging body of papers reports that plant extracts and plant essential oils are effective antimicrobials against food and grain storage fungi $(1,5,8,9,20-$ $22,28,34,38)$, foliar pathogens $(16,24,27$, $29,33,36)$, soilborne fungi $(2,4,10,13,14$, $23,25,30)$, and nematodes (37). In most reports, however, the efficacy of plant extracts and plant essential oils has been evaluated only in vitro, and efficacy data in soil are lacking. In this report, several commercially formulated plant extracts and essential oils were evaluated for their effectiveness in reducing populations of F. oxysporum in soil and controlling wilt development in muskmelon as a model system for other Fusarium wilt diseases. We infested soil with conidia and chlamydospores of $F$. oxysporum, treated the soil with dilutions of the formulated products under standard conditions, and assessed populations of $F$. oxysporum and disease development over time. If natural plant products can reduce populations of soilborne plant pathogens and control disease development, then these plant extracts have potential as environmentally sound alternatives to methyl bromide in integrated management programs. Portions of this research have been reported previously $(6,7)$.

\section{MATERIALS AND METHODS}

Inoculum preparation. For laboratory experiments, an isolate of Fusarium oxysporum f. sp. chrysanthemi from chrysanthemum designated as YBCC 0010 was used (A. Bishop, Yoder Brothers, Inc., Alva, FL). For greenhouse experiments, four isolates of Fusarium oxysporum f. sp. melonis with different levels of virulence 
(J. H. Bowers and J. C. Locke, unpublished) and designated as Fom.-1, Fom.1A, 622A, and 660A (R. Larkin, USDA, Beltsville, MD) were pooled in order to provide a broad test. Inoculum of $F$. oxysporum was produced in an aqueous suspension of $1 \%$ ground soybean hull fiber (Dietfiber soy fiber, Lauhoff Grain Co., Danville, IL) placed on an orbital shaker at $135 \mathrm{rpm}$ for approximately 4 weeks at room temperature. The inoculum was then homogenized in a blender for $1.0 \mathrm{~min}$, quantified using a hemacytometer, and incorporated into recolonized greenhouse soil at a level depending on the experimental protocol described below. Pasteurized soil was subjected to natural recolonization by airborne microorganisms in the greenhouse by exposure to the greenhouse environment before infestation with $F$. oxysporum. Inoculum consisted mostly of microconidia with approximately $10 \%$ chlamydospores and a much lower percentage of macroconidia. Infested soil was then incubated in a shaded portion of the greenhouse, either in plastic bags or in covered tubs, for 5 days before use in laboratory or greenhouse experiments in order to simulate natural inoculum, which is primarily chlamydospores. Inoculum density after the incubation period was typically one-half the amount applied as determined by dilution plating on selective medium as described below. Uninfested soil was used as a control.

Treatments. The experimental treatments for both the population density experiments in the lab and the disease control experiments in the greenhouse were identical. Experimental treatments were: (1) uninfested soil, only water added as a check for residual populations of $F$. oxysporum (not included in analysis); (2) infested soil, only water added; (3) clove (70\% formulated clove oil, Thermo Trilogy Corp., Columbia, MD); (4) neem (90\% formulated neem oil, Triact $90 \mathrm{EC}$, Thermo Trilogy Corp., Columbia, MD); (5) pepper/mustard (formulated chili extract and essential oil of mustard, Insect Control Concentrate, Champon's 100\% Natural Products Inc., Pompano Beach, FL); (6) cassia (formulated extract of cassia tree, Cut In, Abion Co., Tokyo, Japan); and (7) Banrot fungicide (etridiazole and thiophanate-methyl, 40\% WP, The Scotts Co., Marysville, $\mathrm{OH})$. The formulated extracts were compared as 1, 5, and $10 \%$ aqueous emulsions in independent trials of the experiment. With the absence of benomyl for the ornamental market, Banrot, a standard, broad-spectrum combination fungicide labeled for the control of diseases caused by soilborne plant pathogens including Fusarium, was incorporated at low, medium, and high labeled rates $(0.432,0.864$, and $1.296 \mathrm{mg}$ a.i./ml, corresponding with 4,8 , and 12 oz per 100 gal, respectively) in the 1,5 , and $10 \%$ extract trials, respectively.
Population density in the laboratory. For laboratory experiments, $F$. oxysporum f. sp. chrysanthemi was incorporated into soil (previously sifted through a 2-mm sieve) at an inoculum density of $1.1 \times 10^{6}$ spores per $\mathrm{cm}^{3}$. Aliquots $\left(150 \mathrm{~cm}^{3}\right)$ of the infested and control soils were placed in sterile 400-ml beakers and covered with a double layer of aluminum foil. Soil was treated by thoroughly mixing $5.0 \mathrm{ml}$ of 1 , 5 , or $10 \%$ aqueous emulsions of formulated extracts into the soil in each of three beakers (replications of the experimental unit) per treatment. Population densities of $F$. oxysporum f. sp. chrysanthemi were determined using dilution plate techniques at 0 (before soil treatment), 1, 3, 7, 14, and 21 days after soil treatment. Fifteen cubic centimeters of soil (sample unit) from each beaker (replication) was placed in $135 \mathrm{ml}$ of $0.1 \%$ water agar and serially diluted 10 fold. One milliliter from the appropriate dilution (depending on the treatment) was pipetted onto the surface of each of three petri plates containing Komada's medium (15), which is semiselective for $F$. oxysporum. Plates were incubated at room temperature in the dark for 5 to 6 days, at which time colonies of $F$. oxysporum f. sp. chrysanthemi were counted. The average population density for the three replications per treatment at each assay date was calculated and used in the analysis of treatment effects. Eleven trials of the experiment were conducted, and all extract and concentration combinations were repeated at least once in different trials.

Disease control in the greenhouse. Similar population density results were obtained with both $F$. oxysporum f. sp. chrysanthemi and $F$. oxysporum f. sp. melonis in separate studies (J. H. Bowers and J. C. Locke, unpublished); however, Fusarium wilt on muskmelon was used as a model system in greenhouse studies due to rapid and consistent symptom development compared with Fusarium wilt of chrysanthemum. In greenhouse experiments, inocula from the four isolates of $F$. oxysporum f. sp. melonis were pooled and incorporated into soil (not sifted) using a cement mixer at an inoculum density of $2.5 \times 10^{4}$ spores per $\mathrm{cm}^{3}$ of soil. After a 5-day incubation period, soil was treated by incorporating $84 \mathrm{ml}$ of 1,5 , or $10 \%$ aqueous emulsions of formulated extracts into 2.5 liters of soil (experimental unit, one replicate per trial of the experiment) using a Hobart mixer (Hobart Corp., Troy, $\mathrm{OH}$ ). The rates are equivalent to $5.0 \mathrm{ml}$ of aqueous emulsion in $150 \mathrm{~cm}^{3}$ of soil as described above for the population density experiment. Treated soil was placed in double polyethylene bags that were then closed tightly and incubated as above for an additional 7 days. Banrot was applied at the same labeled rates as above. After an additional 7 days of incubation, soil from each treatment (2.5 liters) was placed in seven 10$\mathrm{cm}$-diameter standard plastic pots (sam- pling units are subdivisions of the experimental unit), and five seeds of muskmelon cv. Gold Star (Harris Seeds, Rochester NY) were planted in the soil in each pot. Pots were placed randomly on the greenhouse bench. Emergence was counted after 2 weeks, and plants were assessed for symptom development (wilting and foliar and stem chlorosis and necrosis) beginning 2 weeks after planting, and weekly thereafter. The proportion of symptomless plants was recorded for each extract and concentration combination at each assay date and expressed in terms of the proportion of symptomless plants based on the number of plants at emergence. Three complete trials of the experiment (repetitions) with all extract and concentration combinations were conducted at different times of the year with different greenhouse temperatures. Week 2 was not included in the analysis due to lack of symptom development in most treatments.

Analysis. Data from the laboratory population density experiments were transformed as $\log _{10}\left(\mathrm{CFU} / \mathrm{cm}^{3}\right)$ of soil before analysis. Data from the disease control experiments in the greenhouse were transformed as the arcsine of the square root of the proportion of symptomless plant stand. Both laboratory and greenhouse experiments were analyzed as repeated-measure designs, and analysis of variance was determined using the MIXED procedure in SAS (Statistical Analysis System, Cary, NC). Time was the repeated variable (not a continuous regressor variable), and trial of the experiment was the random variable in all analyses. The fixed effects were extract and concentration. For the purpose of analysis, concentration was nested within extract since the fungicide concentrations were different than the formulated extract concentrations. Means of all pairwise comparisons, both among concentrations of a single extract and among extracts at a single concentration, were tested using Fisher's protected least significant difference with significance determined at $P<$ 0.05 for population density experiments in the lab and $P<0.10$ for disease control experiments in the greenhouse. The significance level for the greenhouse experiment was determined before analysis based on the observed variation in plant growth among trials of the experiment due to external greenhouse variables (32).

\section{RESULTS}

Treatment of soil with aqueous emulsions of the botanical extracts resulted in significant differences among formulated extracts and extract concentrations, with significant interactions with time for both the population density experiments in the lab (Table 1) and disease development in the greenhouse (Table 2). Changes over time were not the same among extracts or concentration of extracts; thus results are presented for each time period. Soil treated 
with $1 \%$ aqueous emulsions of the botanical extracts did not significantly reduce the soil populations of $F$. oxysporum f. sp. chrysanthemi (Table 3) or increase symptomless plants of muskmelon (Table 4) compared with the untreated, infested control soil. Treatment of soil with 5 and $10 \%$ aqueous emulsions of the extracts did result in significant differences in population densities $(P<0.05)$ and number of symptomless plants $(P<0.10)$ among treatments at each assay date (Tables 3 and 4 ).

Table 1. Repeated-measures analysis of variance for the effect of treatment of soil with formulated botanical extracts or Banrot and time in days on population density of Fusarium oxysporum f. sp. chrysanthemi ${ }^{\mathrm{z}}$

\begin{tabular}{lrrl}
\hline Source & df & $\boldsymbol{F}$ value & $\boldsymbol{P}>\boldsymbol{F}$ \\
\hline Extract & 5 & 197.27 & 0.0001 \\
Conc (extract) & 10 & 112.28 & 0.0001 \\
Day & 4 & 16.34 & 0.0001 \\
Day*extract & 20 & 35.81 & 0.0001 \\
Day*conc (extract) & 40 & 13.75 & 0.0001 \\
\hline
\end{tabular}

${ }^{\mathrm{z}}$ Data were transformed as $\log _{10}\left(\mathrm{CFU} / \mathrm{cm}^{3}\right.$ soil $)$ before analysis.

Table 2. Repeated-measures analysis of variance for the effect of treatment of soil with formulated botanical extracts or Banrot and time in weeks on symptomless plants of muskmelons growing in soil infested with Fusarium oxysporum f. sp. melonis ${ }^{2}$

\begin{tabular}{lrcc}
\hline Source & df & $\boldsymbol{F}$ value & $\boldsymbol{P}>\boldsymbol{F}$ \\
\hline Extract & 5 & 4.19 & 0.0052 \\
Conc (extract) & 10 & 3.51 & 0.0037 \\
Week & 3 & 117.29 & 0.0001 \\
Week*extract & 15 & 3.54 & 0.0001 \\
Week*conc (extract) & 30 & 1.97 & 0.0070 \\
\hline
\end{tabular}

${ }^{\mathrm{z}}$ Data were transformed using the arcsine-square root transformation before analysis.

Table 3. Soil population densities of Fusarium oxysporum f. sp. chrysanthemi over time as affected by soil treatment with formulated botanical extracts or Banrot

\begin{tabular}{lccclc}
\hline \multirow{2}{*}{$\begin{array}{c}\text { Rate } \\
\text { Treatment }\end{array}$} & \multicolumn{5}{c}{ Days after treatment } \\
\cline { 2 - 6 } $1 \%$ & $\mathbf{1}$ & $\mathbf{7}$ & $\mathbf{1 4}$ & $\mathbf{2 1}$ \\
\cline { 2 - 6 } Untreated & $5.44 \mathrm{a}^{\mathrm{z}}$ & $5.48 \mathrm{a}$ & $5.51 \mathrm{a}$ & $5.47 \mathrm{a}$ & $5.38 \mathrm{ab}$ \\
Clove & $5.29 \mathrm{a}$ & $5.42 \mathrm{a}$ & $5.37 \mathrm{a}$ & $5.20 \mathrm{a}$ & $5.29 \mathrm{ab}$ \\
Neem & $5.23 \mathrm{a}$ & $5.47 \mathrm{a}$ & $5.45 \mathrm{a}$ & $5.53 \mathrm{a}$ & $5.47 \mathrm{ab}$ \\
Pep/must & $5.32 \mathrm{a}$ & $5.44 \mathrm{a}$ & $5.37 \mathrm{a}$ & $5.41 \mathrm{a}$ & $5.52 \mathrm{a}$ \\
Cassia & $5.43 \mathrm{a}$ & $5.52 \mathrm{a}$ & $5.37 \mathrm{a}$ & $5.55 \mathrm{a}$ & $5.41 \mathrm{ab}$ \\
Banrot (low) & $5.44 \mathrm{a}$ & $5.51 \mathrm{a}$ & $5.41 \mathrm{a}$ & $5.38 \mathrm{a}$ & $5.28 \mathrm{~b}$ \\
$5 \%$ & & & & & \\
Untreated & $5.44 \mathrm{ab}$ & $5.48 \mathrm{ab}$ & $5.51 \mathrm{ab}$ & $5.47 \mathrm{~b}$ & $5.38 \mathrm{~b}$ \\
Clove & $5.17 \mathrm{bc}$ & $5.19 \mathrm{c}$ & $5.32 \mathrm{~b}$ & $5.43 \mathrm{~b}$ & $5.40 \mathrm{~b}$ \\
Neem & $5.68 \mathrm{a}$ & $5.95 \mathrm{a}$ & $6.01 \mathrm{a}$ & $6.01 \mathrm{a}$ & $6.03 \mathrm{a}$ \\
Pep/must & $4.73 \mathrm{c}$ & $1.77 \mathrm{~d}$ & $1.54 \mathrm{c}$ & $3.28 \mathrm{c}$ & $3.95 \mathrm{c}$ \\
Cassia & $4.98 \mathrm{c}$ & $5.30 \mathrm{bc}$ & $5.37 \mathrm{~b}$ & $5.63 \mathrm{ab}$ & $5.30 \mathrm{~b}$ \\
Banrot (med) & $5.53 \mathrm{ab}$ & $5.64 \mathrm{ab}$ & $5.37 \mathrm{~b}$ & $5.18 \mathrm{~b}$ & $5.25 \mathrm{~b}$ \\
10\% & & & & & \\
Untreated & $5.44 \mathrm{a}$ & $5.48 \mathrm{~b}$ & $5.51 \mathrm{~b}$ & $5.47 \mathrm{~b}$ & $5.38 \mathrm{~b}$ \\
Clove & $3.70 \mathrm{~b}$ & $3.90 \mathrm{c}$ & $4.14 \mathrm{c}$ & $4.52 \mathrm{c}$ & $4.54 \mathrm{c}$ \\
Neem & $5.55 \mathrm{a}$ & $5.91 \mathrm{a}$ & $6.02 \mathrm{a}$ & $5.91 \mathrm{a}$ & $5.98 \mathrm{a}$ \\
Pep/must & $3.07 \mathrm{c}$ & $0.83 \mathrm{~d}$ & $1.28 \mathrm{e}$ & $1.50 \mathrm{~d}$ & $2.95 \mathrm{~d}$ \\
Cassia & $3.98 \mathrm{~b}$ & $4.09 \mathrm{c}$ & $3.41 \mathrm{~d}$ & $4.41 \mathrm{c}$ & $3.89 \mathrm{~d}$ \\
Banrot (hi) & $5.63 \mathrm{a}$ & $5.44 \mathrm{~b}$ & $5.34 \mathrm{~b}$ & $5.23 \mathrm{~b}$ & $5.21 \mathrm{~b}$ \\
\hline
\end{tabular}

${ }^{x}$ Soil was treated with 1,5 , or $10 \%$ aqueous emulsions of the formulated products as described in text. Rates of Banrot for low, medium, and high are 0.432, 0.864, and $1.296 \mathrm{mg}$ a.i./ml, respectively.

${ }^{\mathrm{y}}$ Mean values are $\log _{10}$ transformation of $\mathrm{CFU} / \mathrm{cm}^{3}$ of soil. Data represent average of 11 trials of experiment with three replications per treatment per trial. Average soil population density at 0 time (before treatment) was 5.34.

${ }^{z}$ Under each concentration of emulsion, mean values in the same column followed by the same letter are not significantly different at $P=0.05$ based on Fisher's protected least significant difference. infested soil with a $10 \%$ aqueous emulsion of the clove extract also significantly increased $(P=0.08)$ symptomless plant stand 6 weeks after planting in the greenhouse compared with the untreated, infested control soil (Table 4). However, muskmelon plants in the greenhouse growing in soil treated with the clove extract were stunted and showed phytotoxic effects (chlorosis and marginal necrosis different from wilt symptoms) at the $10 \%$ rate. In both the population density and disease control experiments, treatment of soil with the $10 \%$ aqueous emulsion significantly reduced $F$. oxysporum f. sp. chrysanthemi populations and increased the percentage of symptomless plants at the completion of the experiments compared with treatment of the soil with the 1 or $5 \%$ aqueous emulsion (Table 5).

The formulated pepper/mustard extract, added to soil as either a 5 or $10 \%$ aqueous emulsion, significantly reduced $(P=$ $0.0001)$ the population density of $F$. oxysporum f. sp. chrysanthemi in soil $99.9 \%$ after 3 days of incubation compared with untreated, infested soil (Table 3). The reduction in $F$. oxysporum f. sp. chrysanthemi population densities after 3 days was significantly greater $(P=0.0001)$ than that achieved with either the clove or cassia extracts. However, when the formulated pepper/mustard extract was added to soil as a 5 or $10 \%$ aqueous emulsion, the population densities of $F$. oxysporum $\mathrm{f}$. sp. chrysanthemi, which were initially reduced to low levels after 3 days $\left(\log _{10}\left(\mathrm{CFU} / \mathrm{cm}^{3}\right)\right.$ $=1.77$ and 0.83 for the 5 and $10 \%$ emulsions, respectively), increased over time. After 21 days of incubation, the population density of $F$. oxysporum f. sp. chrysanthemi in soil treated with a $5 \%$ aqueous emulsion of the pepper/mustard extract $\left(\log _{10}\left(\mathrm{CFU} / \mathrm{cm}^{3}\right)=3.95\right)$ still was significantly less $(P=0.0001)$ than populations in soil treated with $5 \%$ aqueous emulsions of the other extracts or in the untreated infested soil (Table 3). In soil treated with a $10 \%$ aqueous emulsion of the pepper/mustard extract, the population of $F$. oxysporum f. sp. chrysanthemi after 21 days $\left(\log _{10}\left(\mathrm{CFU} / \mathrm{cm}^{3}\right)=2.95\right)$ was not significantly different $(P=0.196)$ from the population in soil treated with a $10 \%$ aqueous emulsion of the cassia extract. Population densities of $F$. oxysporum f. sp. chrysanthemi in the soil treated with a $10 \%$ aqueous emulsion of pepper/mustard extract were significantly less $(P=0.0001)$ than populations in soil treated with a $5 \%$ aqueous emulsion of the pepper/mustard extract after 21 days (Table 5).

In greenhouse experiments, the pepper/mustard extract added to soil as either a 5 or $10 \%$ aqueous emulsion significantly increased $(P=0.07$ and $P=0.004$, respectively) symptomless plant stand 6 weeks after planting compared with the untreated, infested control soil (Table 4). The percentage of symptomless plant stand in soil 
treated with a $5 \%$ aqueous emulsion of the pepper/mustard extract was numerically greater but not significantly different from that of the cassia treatment 6 weeks after planting. In soil treated with $10 \%$ aqueous emulsions, the pepper/mustard and cassia treatments controlled disease development equally well and had a significantly greater percentage of symptomless plant stand $(P$ $=0.0951)$ than plants growing in soil treated with a $10 \%$ aqueous emulsion of the clove extract 6 weeks after planting. Treatment of soil with either the 5 or $10 \%$ aqueous emulsion significantly increased the percentage of symptomless plants at the completion of the experiments compared with treatment of the soil with the $1 \%$ aqueous emulsion, even though treatment of soil with the $10 \%$ aqueous emulsion resulted in a numerically higher percentage of symptomless plant stand (Table 5).

The formulated cassia extract, only when added to soil as a $10 \%$ aqueous emulsion, significantly reduced $(P=$ $0.0001)$ the population density of $F$. oxysporum f. sp. chrysanthemi in soil $96.1 \%$ after 3 days of incubation compared with the untreated, infested control soil (Table 3). Population densities of $F$. oxysporum $\mathrm{f}$. sp. chrysanthemi remained numerically consistent over time, and after 21 days of incubation, were not significantly different $(P=0.196)$ from $F$. oxysporum f. sp. chrysanthemi populations in soil treated with a $10 \%$ aqueous emulsion of the pep- per/mustard extract. Populations of $F$. oxysporum f. sp. chrysanthemi were significantly less $(P=0.0001)$ when soil was treated with a $10 \%$ aqueous emulsion of the formulated cassia extract than in soil treated with a $10 \%$ aqueous emulsion of the clove extract after 21 days. Population densities of $F$. oxysporum f. sp. chrysanthemi in the soil treated with a $10 \%$ aqueous emulsion of cassia extract were significantly less $(P=0.0001)$ than populations in soil treated with a $5 \%$ aqueous emulsion of the cassia extract at the completion of the experiment (Table 5).

The cassia extract, added to soil as either a 5 or $10 \%$ aqueous emulsion, significantly increased $(P=0.096$ and $P=0.004$, respectively) symptomless plant stand in the greenhouse 6 weeks after planting compared with the untreated, infested control soil (Table 4). Even though Fusarium population densities were numerically greater in soil treated with a $10 \%$ aqueous emulsion of the cassia extract than in soil treated with a $10 \%$ aqueous emulsion of the pepper/mustard extract (Table 3), a similar, high level of disease control occurred in the greenhouse (Table 4). Treatment of soil with the $10 \%$ aqueous emulsion significantly increased the percentage of symptomless plants at the completion of the experiment compared with treatment of the soil with the 1 or $5 \%$ aqueous emulsion (Table 5). Treatment of soil with the $5 \%$ aqueous emulsion of the cassia extract significantly increased the

Table 4. Symptomless plants of muskmelon growing in soil infested with Fusarium oxysporum f. sp. melonis over time as affected by soil treatment with formulated botanical extracts or Banrot

\begin{tabular}{lccccc}
\hline \multirow{2}{*}{$\begin{array}{c}\text { Rate } \\
\text { Treatment }\end{array}$} & \multicolumn{5}{c}{ Weeks after planting } \\
\cline { 2 - 5 } 1\% & $\mathbf{2}$ & $\mathbf{3}$ & $\mathbf{4}$ & $\mathbf{5}$ & $\mathbf{6}$ \\
Untreated & $95.6^{\mathrm{y}} \mathrm{a}^{\mathrm{z}}$ & $83.8 \mathrm{a}$ & $64.9 \mathrm{a}$ & $57.2 \mathrm{ab}$ & $38.2 \mathrm{a}$ \\
Clove & 100.0 & $80.1 \mathrm{a}$ & $59.7 \mathrm{a}$ & $40.6 \mathrm{~b}$ & $23.9 \mathrm{a}$ \\
Neem & $98.9 \mathrm{a}$ & $86.1 \mathrm{a}$ & $80.7 \mathrm{a}$ & $70.3 \mathrm{a}$ & $52.8 \mathrm{a}$ \\
Pep/must & 100.0 & $82.8 \mathrm{a}$ & $66.2 \mathrm{a}$ & $59.0 \mathrm{ab}$ & $46.3 \mathrm{a}$ \\
Cassia & $98.0 \mathrm{a}$ & $82.2 \mathrm{a}$ & $69.1 \mathrm{a}$ & $49.7 \mathrm{ab}$ & $32.4 \mathrm{a}$ \\
Banrot (low) & 100.0 & $87.4 \mathrm{a}$ & $63.8 \mathrm{a}$ & $53.0 \mathrm{ab}$ & $34.5 \mathrm{a}$ \\
5\% & & & & & \\
Untreated & $95.6 \mathrm{a}$ & $83.8 \mathrm{ab}$ & $64.9 \mathrm{~b}$ & $57.2 \mathrm{c}$ & $38.2 \mathrm{~b}$ \\
Clove & 100.0 & $88.4 \mathrm{ab}$ & $70.8 \mathrm{~b}$ & $46.9 \mathrm{c}$ & $28.3 \mathrm{~b}$ \\
Neem & $98.1 \mathrm{a}$ & $70.4 \mathrm{~b}$ & $67.4 \mathrm{~b}$ & $67.4 \mathrm{~b}$ & $57.7 \mathrm{ab}$ \\
Pep/must & 100.0 & $98.9 \mathrm{a}$ & $98.9 \mathrm{a}$ & $95.7 \mathrm{a}$ & $83.9 \mathrm{a}$ \\
Cassia & 100.0 & $92.2 \mathrm{ab}$ & $89.2 \mathrm{a}$ & $85.1 \mathrm{ab}$ & $73.8 \mathrm{a}$ \\
Banrot (med) & 100.0 & $93.2 \mathrm{ab}$ & $86.5 \mathrm{ab}$ & $67.2 \mathrm{bc}$ & $38.2 \mathrm{~b}$ \\
10\% & & & & & \\
Untreated & 95.6 & $83.8 \mathrm{ab}$ & $64.9 \mathrm{ab}$ & $57.2 \mathrm{~cd}$ & $38.2 \mathrm{c}$ \\
Clove & 100.0 & $96.6 \mathrm{a}$ & $92.1 \mathrm{a}$ & $88.8 \mathrm{ab}$ & $83.5 \mathrm{~b}$ \\
Neem & 100.0 & $62.5 \mathrm{~b}$ & $49.4 \mathrm{~b}$ & $40.1 \mathrm{~d}$ & $31.9 \mathrm{c}$ \\
Pep/must & 100.0 & 100.0 & 100.0 & 100.0 & $99.0 \mathrm{a}$ \\
Cassia & 100.0 & 100.0 & 100.0 & $99.0 \mathrm{a}$ & $99.0 \mathrm{a}$ \\
Banrot (hi) & 100.0 & $95.7 \mathrm{a}$ & $88.3 \mathrm{a}$ & $73.8 \mathrm{bc}$ & $37.6 \mathrm{c}$ \\
\hline
\end{tabular}

${ }^{x}$ Soil was treated with 1,5 , or $10 \%$ aqueous emulsions of the formulated products as described in text. Rates of Banrot for low, medium, and high are 0.432, 0.864, and $1.296 \mathrm{mg}$ a.i./ml, respectively.

${ }^{y}$ Mean values are percent symptomless plants. Data represent average of three trials of experiment with seven pots per treatment and five plants per pot. For analysis, data were transformed as the arcsine of the square root of symptomless plants expressed as a proportion of emergence at 2 weeks.

${ }^{\mathrm{z}}$ Under each concentration of emulsion, mean values in the same column followed by the same letter are not significantly different at $P=0.10$ based on Fisher's protected least significant difference.

percentage of symptomless plants at the completion of the experiments compared with treatment of the soil with the $1 \%$ aqueous emulsion, even though there were no differences in population densities between soils treated with 1 or $5 \%$ aqueous emulsions of the cassia extract (Table 5).

The treatment of the soil with a formulated neem oil extract, added to soil as 5 or $10 \%$ aqueous emulsions, significantly increased the population densities of $F$. oxysporum f. sp. chrysanthemi (Table 3) and had no significant effect on plant stand in the greenhouse 6 weeks after planting compared with the untreated infested soil (Table 4). There were no differences among the 1,5 , or $10 \%$ aqueous neem oil emulsions with regard to population densities of F. oxysporum f. sp. chrysanthemi or

Table 5. Soil population densities of Fusarium oxysporum f. sp. chrysanthemi and symptomless plants of muskmelon growing in soil infested with Fusarium oxysporum f. sp. melonis at the completion of the experiments as affected by soil treatment with formulated botanical extracts or Banrot

\begin{tabular}{clc}
\hline $\begin{array}{c}\text { Treatment } \\
\text { Rate }\end{array}$ & $\begin{array}{l}\log _{10} \\
\left(\mathbf{C F U} / \mathbf{c m}^{\mathbf{3}}\right)^{\mathbf{x}}\end{array}$ & $\begin{array}{c}\text { \% plant } \\
\text { stand }^{\mathbf{y}}\end{array}$ \\
\hline Clove & & \\
$1 \%$ & $5.29 \mathrm{a}^{\mathrm{z}}$ & $23.9 \mathrm{~b}$ \\
$5 \%$ & $5.40 \mathrm{a}$ & $28.3 \mathrm{~b}$ \\
$10 \%$ & $4.54 \mathrm{~b}$ & $83.5 \mathrm{a}$ \\
Neem & & \\
$1 \%$ & $5.47 \mathrm{a}$ & $52.8 \mathrm{a}$ \\
$5 \%$ & $6.03 \mathrm{a}$ & $57.7 \mathrm{a}$ \\
$10 \%$ & $5.98 \mathrm{a}$ & $31.9 \mathrm{a}$ \\
Pep/must & & \\
$1 \%$ & $5.52 \mathrm{a}$ & $46.3 \mathrm{~b}$ \\
$5 \%$ & $3.95 \mathrm{~b}$ & $83.9 \mathrm{a}$ \\
$10 \%$ & $2.95 \mathrm{c}$ & $99.0 \mathrm{a}$ \\
Cassia & & \\
$1 \%$ & $5.41 \mathrm{a}$ & $32.4 \mathrm{c}$ \\
$5 \%$ & $5.30 \mathrm{a}$ & $73.8 \mathrm{~b}$ \\
$10 \%$ & $3.89 \mathrm{~b}$ & $99.0 \mathrm{a}$ \\
Banrot & & \\
Low & $5.28 \mathrm{a}$ & $34.5 \mathrm{a}$ \\
Med & $5.25 \mathrm{a}$ & $38.2 \mathrm{a}$ \\
High & $5.21 \mathrm{a}$ & $37.6 \mathrm{a}$ \\
\hline
\end{tabular}

${ }^{\text {w }}$ Soil was treated with 1,5 , or $10 \%$ aqueous emulsions of the formulated products. Rates of Banrot for low, medium, and high are $0.432,0.864$, and $1.296 \mathrm{mg}$ a.i. $/ \mathrm{ml}$, respectively.

${ }^{x} F$. oxysporum f. sp. chrysanthemi. Mean values are $\log _{10}\left(\mathrm{CFU} / \mathrm{cm}^{3}\right)$ of soil 21 days after soil treatment. Data represent average of 11 trials of experiment with three replications per treatment per trial. Average soil population density at 0 time (before treatment) was 5.34.

y $F$. oxysporum f. sp. melonis. Mean values are percent symptomless plants 6 weeks after planting. Data represent average of three trials of experiment with seven pots per treatment and five plants per pot. For analysis, data were transformed as the arcsine of the square root of symptomless plants expressed as a proportion of emergence at 2 weeks.

z Under each extract, mean values in the same column followed by the same letter are not significantly different at $P=0.05$ for the population density experiment and $P=0.10$ for the disease control experiment based on Fisher's protected least significant difference. 
symptomless plant stand in the greenhouse at the completion of the experiments (Table 5).

Treatment of the soil with the fungicide Banrot did not significantly reduce the population density of $F$. oxysporum $\mathrm{f}$. sp. chrysanthemi or increase the percentage of symptomless plant stand in the greenhouse compared with the untreated infested soil in any experiment at any rate tested (Tables 3 and 4). Likewise, there were no significant differences among the low, medium, or high rate of Banrot at the completion of either the population density or disease control experiments (Table 5).

\section{DISCUSSION}

Several formulated botanical extracts were shown to effectively reduce soil populations of $F$. oxysporum and increase symptomless plant stand in controlled experiments. The suppression of wilt development in the greenhouse corresponds with the ability of these extracts to reduce populations of Fusarium in soil. The pepper/mustard, cassia, and clove treatments reduced soil populations of $F$. oxysporum $\mathrm{f}$. sp. chrysanthemi in laboratory studies and increased symptomless plant stand in muskmelons growing in soil infested with F. oxysporum f. sp. melonis compared with untreated controls. Based on our studies, different formae speciales of $F$. oxysporum may react in a similar manner to the tested products; thus results obtained in one system may be applicable to another.

The experiments in this study were conducted under controlled and standardized conditions, but with enough variation over time, soil mixtures, and season to yield realistic and applicable results. Our purpose was to determine if these formulated extracts were efficacious when applied to soil. These products are being or were developed for foliar application or other uses, and little or no data exist for their activity in soil. As such, we thoroughly mixed dilutions of the formulations in soil and optimized the conditions for pathogen survival in the laboratory and wilt development in the greenhouse. Under these conditions, we were able to determine with some confidence if any of the formulated extracts were effective and deserving further research. This in situ approach would be closer to production conditions than in vitro assays. Based on our results, several extracts, namely the pepper/mustard combination and the cassia- and clove-based formulations, warrant further investigation.

We do not believe, at this time, that these products by themselves in their current formulations can replace methyl bromide or other fumigants and pesticides on a one-for-one basis in all situations. However, these extract formulations may develop into components of different management strategies, and would depend on the particular cropping system. Several parameters need to be developed in order to scale up to field or nursery conditions, such as delivery method, appropriate formulation for delivery and soil type, rate, cultural practices, and economic factors involved. Consideration will need to be given to the mechanism of the interaction of the product with the pathogen population and the host plant. Many plant extracts have volatile components, essential oils, and so on. Preliminary data suggest that some of these extracts and essential oils are capable of pathogen growth inhibition in vitro when tested so that only volatiles interact with the pathogen, while others only inhibit the pathogen when in direct contact (J. H. Bowers and J. C. Locke, unpublished). Information of this type is important as one tries to develop a delivery system that utilizes the extracts' physical and chemical properties.

The effect of an extract on the target pathogen population over time also is an issue when determining whether repeated soil treatment is necessary throughout the growing season. For example, soil populations of $F$. oxysporum f. sp. chrysanthemi were lowest after 3 to 7 days of incubation when the soil was treated with 5 and $10 \%$ aqueous emulsions of the formulated pepper/mustard extract. Population numbers then increased over time. In greenhouse experiments, the pepper/mustard extract controlled disease initially, but disease incidence increased later in the experiments, especially with the $5 \%$ aqueous emulsion. Fusarium populations may have increased, as in the laboratory studies, to sufficient levels in the greenhouse over time to cause symptom development. Observation of the lack of background microflora on dilution plates suggests that the pepper/mustard extract may act as a general biocide. At this concentration, the extract may affect a wide range of soil microorganisms and thus may create a biological vacuum. Fusarium has been shown to rapidly colonize fumigated soil in the absence of competition $(17,19)$. We hypothesize that the extract may break down rapidly in soil, and a small surviving population of Fusarium may have flourished in the soil environment with the natural microflora at low population levels once the active ingredient in the extract was no longer present. Treatment of soil with a $5 \%$ aqueous emulsion may not have reduced Fusarium populations enough, thus allowing rapid recolonization with reduced microbial competition, to effectively control disease over a long time frame. Populations of Fusarium also increased numerically over time when the pepper/mustard extract was added as a $10 \%$ aqueous emulsion. However, disease control was nearly $100 \%$ during the 6 weeks of the experiment in the greenhouse. Treatment of the soil with a $10 \%$ aqueous emulsion of the pepper/mustard extract may have reduced Fusarium populations sufficiently to suppress disease over a longer period of time. A very low Fusarium population may not compete as well over time with other soil populations during recolonization (26). Thus, any threshold needed for observable symptom development may be delayed. It is within this time frame that the addition of biological control microorganisms may be most effective (19). Retreatment of soil during the growing period may not be feasible with the pepper/mustard extract because of potential phytotoxicity (J. H. Bowers and J. C. Locke, unpublished). Season-long disease control in the field needs to be evaluated.

The cassia extract, on the other hand, did not reduce Fusarium populations to the extent that the pepper/mustard extract did, but suppressed disease development to the same degree as the pepper/mustard extract when added to soil as a $10 \%$ aqueous emulsion. We hypothesize, based on observations from dilution plates, that the cassia extract did not have as wide a biocidal effect but may be selective for Fusarium and related fungi. Potentially beneficial fungi may not be affected and may actually increase in numbers. These groups of organisms could suppress disease development in the presence of the pathogen. Further evidence of this phenomenon may be evident in treatments when the cassia extract was added as a $5 \%$ aqueous emulsion. Soil populations of Fusarium were not reduced compared with the untreated, infested soil; yet disease was suppressed by evidence of an increase in symptomless plants. Biological factors may be involved. The microbial ecology of the soil biota needs to be investigated and comparisons made between treatments with the pepper/mustard and cassia extracts in order to test this hypothesis.

While the clove treatment reduced soil populations and increased the percentage of symptomless plants when added to soil as a $10 \%$ aqueous emulsion, its utility as a component in a management strategy is questionable because of pronounced phytotoxicity at concentrations needed to reduce soil pathogen populations. The use of clove may be feasible with changes in formulation or application methods, but more research is needed.

The withdrawal of Benlate, a standard for the control of Fusarium wilt diseases, from the ornamental market leaves a void in available chemical management options outside of fumigation. Banrot did not reduce Fusarium populations in soil or reduce disease development. The observed reduction in the Fusarium population and increased symptomless plant stand in the greenhouse suggests that natural plant extracts may have important roles in biologically based management strategies. One plausible scenario is that a natural extract be incorporated into soil to initially reduce the pathogen population. This would be followed 1 to 2 weeks later by 
application of a biological agent, which may or may not need to be compatible with the extract. The organism may need only to be capable of rapid colonization of the treated soil in order to suppress reestablishment or proliferation of the pathogen, or the organism may interact with the pathogen and/or host in some manner, thus achieving disease control $(18,19,31)$. Initial experiments in the greenhouse to test this strategy have had favorable results, where the addition of a biological control agent in combination with the pepper/mustard extract resulted in increased symptomless plant stand over either the biological agent or the pepper/mustard extract used alone (J. H. Bowers and J. C. Locke, unpublished). Further research in this area has the potential to extend the usefulness of natural plant products and other biopesticides in crop production systems.

\section{ACKNOWLEDGMENTS}

We thank Ellen Alpano, Jo-Anne Alpano, and Rebecca Bierman for their expert technical assistance, Andrew Bishop and Robert Larkin for providing cultures of Fusarium oxysporum, Mary Camp and Brian Vineyard, USDA, ARS, Biometrical Consulting Service, for statistical consultation, and Don Ferrin and Doug Mills for their critical reviews of the manuscript.

\section{LITERATURE CITED}

1. Arras, G., Piga, A., and D'Hallewin, G. 1993. The use of Thymus capitatus essential oil under vacuum conditions to control Penicillium digitatum development on citrus fruit. Acta Hortic. 344:147-153.

2. Awuah, R. T. 1994. In vivo use of extracts from Ocimum gratissimum and Cymbopogon citratus against Phytophthora palmivora causing blackpod disease of cocoa. Ann. Appl. Biol. 124:173-178.

3. Beckman, C. H. 1987. The Nature of Wilt Diseases of Plants. American Phytopathological Society, St. Paul, MN.

4. Bianchi, A., Zambonelli, A., Zechini D'Aulerio, A., and Bellesia, F. 1997. Ultrastructural studies of the effects of Allium sativum on phytopathogenic fungi in vitro. Plant Dis. 81:1241-1246.

5. Bishop, C. D., and Thorton, I. B. 1997. Evaluation of the antifungal activity of the essential oils of Monarda citriodora var. citriodora and Melaleuca alternifolia on post-harvest pathogens. J. Essential Oil Res. 9:77-82.

6. Bowers, J. H., and Locke, J. C. 1997. Effect of botanical extracts on the population density of Fusarium oxysporum f. sp. chrysanthemi in soil. (Abstr.) Phytopathology 87:S11.

7. Bowers, J. H., and Locke, J. C. 1998. Effect of botanical extracts on Fusarium wilt of muskmelon in the greenhouse. (Abstr.) Phytopathology 88:S10.

8. Chatterjee, D. 1989. An effective formulation for mould- and aflatoxin-free storage of corn. Lett. Appl. Microbiol. 9:25-28.

9. Dixit, S. N., Chandra, H., Tiwari, R., and Dixit, V. 1995. Development of a botanical fungicide against blue mould of mandarins. J. Stored Prod. Res. 31:165-172.

10. Dubey, N. K., and Kishore, N. 1987. Fungitoxicity of some higher plants and synergistic activity of their essential oils. Trop. Sci. 27:23-27.

11. Grange, M., and Ahmed, S. 1988. Handbook of Plants with Pest Control Properties. John Wiley \& Sons, New York.

12. Grayer, R. J., and Harborne, J. B. 1994. A survey of antifungal compounds from higher plants, 1982-1993. Phytochemistry 37:19-42.

13. Kishore, N., Dixit, S. N., and Dubey, N. K. 1989. Fungitoxic studies with Chenopodium ambrosioides for control of damping-off in Phaseolus aureus (Moong) caused by Rhizoctonia solani. Trop. Sci. 29:171-176.

14. Kishore, N., Srivastava, O. P., Dubey, N. K., and Dixit, S. N. 1982. Evaluation of the essential oil from the inflorescence of Chenopodium ambrosioides $\mathrm{L}$. against Rhizoctonia solani. Indian Perfum. 26:228-230.

15. Komada, H. 1975. Development of a selective medium for quantitative isolation of Fusarium oxysporum from natural soil. Rev. Plant Prot. Res. 8:114-125.

16. Lawson, M., and Kennedy, R. 1998. Evaluation of garlic oil and other chemicals for control of downy mildew (Peronospora parasitica) in organic production of brassicas. Ann. Appl. Biol. 132(suppl.):14-15.

17. Marois, J. J., Dunn, M. T., and Papavizas, G. C. 1983. Reinvasion of fumigated soil by Fusarium oxysporum f. sp. melonis. Phytopathology 73:680-684.

18. Marois, J. J., and Mitchell, D. J. 1981. Effects of fumigation and fungal antagonists on the relationships of inoculum density to infection incidence and disease severity in Fusarium crown rot of tomato. Phytopathology 71:167170.

19. Marois, J. J., and Mitchell, D. J. 1981. Effects of fungal communities on the pathogenic and saprophytic activities of Fusarium oxysporum f. sp. radicis-lycopersici. Phytopathology 71:1251-1256.

20. Mishra, A. K., and Dubey, N. K. 1994. Evaluation of some essential oils for their toxicity against fungi causing deterioration of stored food commodities. Appl. Environ. Microbiol. 60:1101-1105.

21. Moleyar, V., and Narasimham, P. 1986. Antifungal activity of some essential oil components. Food Microbiol. 3:331-336.

22. Montes-Belmont, R., and Carvajal, M. 1998. Control of Aspergillus flavus in maize with plant essential oils and their components. J. Food Prot. 61:616-619.

23. Muller-Riebau, F., Berger, B., and Yegen, O.
1995. Chemical composition and fungitoxic properties to phytopathogenic fungi of essential oils of selected aromatic plants growing wild in Turkey. J. Agric. Food Chem. 43:2262-2266.

24. Northover, J., and Schneider, K. E. 1993. Activity of plant oils on diseases caused by Podosphaera leucotricha, Venturia inaequalis, and Albugo occidentalis. Plant Dis. 77:152-157.

25. Pandey, V. N., and Dubey, N. K. 1994. Antifungal potential of leaves and essential oils from higher plants against soil phytopathogens. Soil Biol. Biochem. 26:1417-1421.

26. Park, D. 1959. Some aspects of the biology of Fusarium oxysporum Schl. in soil. Ann. Bot. 23:35-49.

27. Pasini, C., D'Aquila, F., Curir, P., and Gullino, M. L. 1997. Effectiveness of antifungal compounds against rose powdery mildew (Sphaerotheca pannosa var. rosae) in glasshouses. Crop Prot. 16:251-256.

28. Paster, N., Menasherov, M., Ravid, U., and Juven, B. 1995. Antifungal activity of oregano and thyme essential oils applied as fumigants against fungi attacking stored grain. $\mathrm{J}$. Food Prot. 58:81-85.

29. Rao, G. P., Singh, M., and Singh, H. N. 1992. Fungitoxic evaluation of essential oils extracted from higher plants against some sugarcane pathogens. Trop. Sci. 32:377-382.

30. Shimoni, M., Putievsky, E., Ravid, U., and Reuveni, R. 1993. Antifungal activity of volatile fractions of essential oils from four aromatic wild plants in Israel. J. Chem. Ecol. 19:1129-1133.

31. Singh, H. B., and Handique, A. K. 1997. Antifungal activity of the essential oil of Hyptis suaveolens and its efficacy in biocontrol measures in combination with Trichoderma harzianum. J. Essential Oil Res. 9:683-687.

32. Steel, R. G. D., and Torrie, J. H. 1980. Principles and Procedures of Statistics: A Biometrical Approach. 2nd ed. McGraw-Hill, New York

33. Tewari, S. N. 1995. Ocimum sanctum L., a botanical fungicide for rice blast control. Trop. Sci. 35:263-273.

34. Thompson, D. P. 1989. Fungitoxic activity of essential oil components on food storage fungi. Mycologia 81:151-153.

35. Tjamos, E. C., and Beckman, C. H. 1989. Vascular Wilt Diseases of Plants: Basic Studies and Control. Springer-Verlag, Berlin.

36. Walker, J. C., Morell, S., and Foster, H. H. 1937. Toxicity of mustard oils and related sulfur compounds to certain fungi. Am. J. Bot 24:536-541.

37. Walker, J. T. 1998. Plant derivatives as potential nematicides. (Abstr.) Phytopathology 88:S92.

38. Wilson, C. L., Solar, J. M., El Ghaouth, A., and Wisniewski, M. E. 1997. Rapid evaluation of plant extracts and essential oils for antifungal activity against Botrytis cinerea. Plant Dis. 81:204-210. 